\title{
Kungfu as a Vehicle for Multimodal Intercultural Communication \\ A Chinese-New Zealand Case Study: Ant Sang's Shaolin Burning (2011) Preliminary Observations
}

By

Fang Zheng

\section{Introduction: Kungfu as (cross)cultural medium}

\subsection{Sport as a vehicle for culture: Kungfu and Chinese culture and identity}

I would argue that in the Chinese-New Zealand case study I am discussing in this article - Ant Sang's Shaolin Burning (2011) - Kungfu corresponds to a collection of Martial Arts techniques that are similar to the traditional/old-style Kungfu novels. For Example, Sifu, Deadly Plum Blossom's (the heroin) Kungfu master, once introduced her understanding of Kungfu in Shaolin Burning (2011): "The most important principle to remember is to protect your centreline. This protects your eyes, neck and all your vital organs... It forces your opponent to attack in a circular path, which is an indirect path, and therefore slower [...] Control the centreline and you control the fight. Not only do you use the centreline for defence, use it also for attack. My punch is unorthodox. It is deceptively short and direct, but when performed correctly has devastating power." (SB 51-54) Those are typical guidelines for Martial Arts techniques.

However, after the most well-known Kungfu Novelist and scriptwriter, Louis Cha (金庸), has added the "internal force" to marital art techniques in 1955, the new-style Kungfu Novel has become the main stream in China. He and other new-style Kungfu novelists, added the "internal force" to marital art works, making "Kungfu" more mysterious, upgrading the Kungfu power system to a higher level, and exceeding the scope of martial arts.

The "internal force" is a concept originated from Ancient Chinese Health preservation and Taoism, a style of philosophy that originated in China (Yuan, 26). A typical example of "internal force" is "Chi" (气). The well-known Disney animation movie Kungfu Panda has introduced Chi: "An Incredible power awaits you, a power beyond anything you can imagine." Chi is "[t]he energy that flows through all living things. Mastering Chi requires mastering of self" (Yuh \& Carloni dir.). Chi is invisible and in order to show it in a visual way, the Panda Pao's Shifu (Master) makes a Taichi gesture, using Chi to make a flower bud bloom immediately. Actually, not only making a bud bloom, in other Kungfu stories in China, masters with Chi can jump very high, even fly in the sky. If they punch someone, it's not necessary for them to touch the opponent's body: one gesture is enough to kick the opponents miles away! These are similar to the superpower in Marvel comics.

In this article I will draw on my personal connection with Kungfu as well as from literary studies and intercultural communication studies in order to discuss sport as a powerful vehicle of culture and also to test multimodality as an ideal framework to 
express and exchange hyphenated identity. What I am offering here are preliminary reflections based on my current research, which I will continue to investigate and evaluate.

\subsection{My personal connection with Kungfu: what does it do for my identity?}

In my childhood, TV drama series based on Louis Cha's Kungfu novels were - and continue to be - very popular and I have become a devoted fan of this genre. In the most traditional Kungfu novels, female characters are like accessories to male characters. They could be described as 'byproducts' of love.

In the stories of female writers, however, this pattern does not exist. Women are independent and not 'vassal' to anyone. When I was 15, I read the first Kungfu story written by a female Kungfu writer, Xuewei Sword. The heroine in the story is one of the top masters in the Marital Arts world. She's powerful, calm and keeps a strong sense of responsibility to ensure the world's harmony. She has a difficult childhood, full of challenges and suffering. Her mother was murdered when she was five. Since then, she has realized the importance of being powerful and strong. This is the first time for me to fully realize that a woman can also become a top master in Kungfu. With wisdom, hard work and strong will, a woman can determine her future and career by herself. Women are no longer accessories to men.

From that moment on I've continued to read female writers' Kungfu stories. These female writers have added their own unique artistic imagination to their literary works. Therefore, women no longer play 'supporting roles' within the Kungfu world, but are the protagonists. Women can also use words and stories drawn from the world of Kungfu.

Translated into real life, these outstanding female writers have become role models for contemporary Chinese women, in that they show women how to strive for and achieve equal rights and access opportunities.

Kungfu works focusing on female characters have been gaining attention from readers and critics alike since 2005 . This period of time is clearly not long enough to influence male Kungfu writers and get them to engage with their female counterparts.

By coincidence, I have come across and read Ant Sang's story, Shaolin Burning. As a male writer and cartoonist, Sang chooses a female character, Deadly Plum Blossom, as the protagonist and relies on her to develop the whole story, which is very rare to see in China. Not only Deadly Plum Blossom but also other female characters in this story, such as Sifu, and Yim Wing Chun, share certain characteristics: they are wise, brave, and independent: similar to the female characters in Chinese Kungfu stories by female writers.

For this reason, I've chosen Shaolin Burning as a case study and have adopted a more poetic and Kungfu style to translate it into Chinese. I believe that this approach can not only be favorably received but also impress Chinese readers in general and Kungfu lovers especially. The Kungfu Style draws on the characteristics of Chinese classical vernacular novels, focusing on the artistic spirit of exaggeration, imagination, 
freehand brushwork and vividness. This style is national, popular and classical.

\section{Ant Sang (1970): a Chinese-New Zealand Cartoonist}

\subsection{Kungfu outside China}

What about Kungfu outside China? Can it represent as adequately Chinese people who have other cultural backgrounds?

The most classical Kungfu style originated from Hong Kong and Taiwan (think, for example, of works by the aforementioned Louis Cha and Liang Yusheng). The new generation of Kungfu writers in mainland China has broken through and brought about innovations based on the traditional Kungfu styles in those original places. Looking at Ant Sang's work, one can see that the classical Kungfu style in Chinese Kungfu is the most influential style outside China. The New Kungfu style has not been fully introduced into countries and canons.

\subsection{Ant Sang's life and work}

Ant Sang (1970), a New Zealand-Chinese cartoonist, is best known for his character and comic book work. His style varies from modern mainstream, such as Helen and the Go-Go Ninjas (2018) and The Dharma Punks (2014), to traditional nouveau like Shaolin Burning (2011) and The Quiet Achiever (2017). As one blogger puts it, "with an acute understanding of composition and form, Ant's art is distinguished by fluid line work and strong characters that display energy and movement." (https://internationalrescue.com/artist/ant-sang/). In his comic work, Ant combines a lot of Chinese cultural elements, especially Kungfu with many Western values, beliefs and narratives. This is the case of his most outstanding work to date is Shaolin Burning (2011).

I am tempted to assume that Ant Sang has read or watched Kungfu works from Louis Cha. Still, he has chosen the old style Kungfu--only Marital Art techniques to tell his stories. Is it because of cultural differences? Is it because it is difficult for Western readers to understand Chi and enjoy the new style of Kungfu? Besides, many American scholars have mentioned that bullying is a very serious issue in schools and teenagers want to learn more practical self-defense techniques. Is there a similar context in New Zealand? Do New Zealand readers prefer marital art techniques rather than invisible and virtual Chi?

\section{Would Sang's artful storytelling work in China? A fascinating 'back translation'}

\subsection{Premises and projections...}


Given the premises I have outlined before, one cannot help asking whether Sang's work and his use of Kungfu would work in China. I would argue that the awareness of gender equality in Sang's work and his use of Kungfu can definitely work in China.

As a man, Ant Sang depicts many impressive female characters in this work, and he expressed feminism and women's power to change and influence the world in Shaolin Burning. As mentioned above, it is rare to see a male Kungfu writer in China choosing a female character's perspective to develop a story or more than half of the story. Meanwhile, female Kungfu novelists would always choose a female character to develop the whole story. It seems to me that those novelists feel it is their duty to call for feminism because of the gender discrimination issues in China. Reading Shaolin Burning, I feel that a man can show sincere respect to women and can give and action to feminine power, something that is very precious to Chinese women.

As the first country to give women the right to vote, New Zealand has set up quite an ideal atmosphere to ensure gender equality. A sound and fair legal protection system, a free and tolerant social policy environment, active and orderly women's groups and feminist movements have given New Zealand women a higher political, economic and social status (Hongmei Shi, Jie Huang 84). Therefore, feminist revolution in culture has taken firms roots in New Zealand, and this may be the reason why male writers in New Zealand can create works based on a female character's point of view.

In contrast, in China female Kungfu novels appeared very late. Before the Internet age, and for a very long time, the Chinese literary world was dominated by men writers. Female writers, and especially noteworthy female writers, were very few. In the Internet age, as publishing one's work has become easier, and the standards of publishable works have been somewhat lowered, more and more people have produced literary works, including female Kungfu writers. As a result, an increasing number of talented female writers bringing out Kungfu novels have emerged.

Therefore, it is a telling exercise to bring Ant Sang's comic works such as Shaolin Burning back home to China not only to showcase women's power but also to better understand the role of two different cultures in one's own identity.

\subsection{Two examples from my translation in progress}

Yim Wing Chun, p. 57:

"[...] she has a crucial fight soon, but has never fought before. She has been granted one year to Prepare [...] she will fight in a year whether she's ready or not. There is no choice in the matter. I will prepare her as best I can in that time [...] I thought you'd feel likewise!"

“这姑娘没有任何武功底子, 但她马上要参加一场殊死搏斗了。她有一年时间准 备。。。无论是否准备妥当, 一年后她都得上场了。她别无选择。为师会在这一 年内尽力帮她提升武学。。为师觉得你也深有同感! ” 
"You are correct. No one expects her to win, but she must [...] if she loses she will be forced to wed a brute who has fallen for her. Her only chance of freedom is to beat him in the challenge match $[\ldots]$ "

“小梅, 你是对的。没人觉得她会嬴。但她必须赢！如果她输了, 她就得如约嫁 给那个畜牲。她唯一获得自由的机会, 就是在那场武斗中打败他! ”

I am very impressed by this character. Yim represents the struggles of women in China (and in Asia) not only in the past but also at present. Well-educated women with decent work and high income are still suffering from a lot of anxiety and pressure from society, most of which come from the expectations to get married. Even nowadays women in Asian lack freedom in terms of marital issues, just like Yim in the story. If someone decides not to get married and have kids all her life, she will face numerous criticisms, interferences and pressures from family, friends, peers and society at large. Most of those pressures come from within the family and more specifically from the parents. Meanwhile, the parents also live under great anxiety and pressure if their daughters are not married. It seems that older generations in China care for other people's criticism very much. They do not have too much awareness of self-identity, even among the mothers from middle and upper class. Parents born after 1960s are experiencing radical change in China during their youth, many of them have experienced poverty in Childhood to a well-off life in mid-life. Their children are grown up in a very different environment from theirs, which has increased the generation gap compare to other countries. Besides, because of the "three pillars of socialism: ideology of collectivism, staged propaganda as well as controlled feminism" (Qi Yan York, 1) which has made them pay too much attention to collectivism, care too much about how others criticize or judge them. That may be the root to cause their anxiety to their children's marital issues: others have got married, then you have to do the same thing. Otherwise, you will be separated and judged as a "loser".

However, in Sang's story Yim manages to figure out a solution: you have to be strong enough to win the battle. No matter how hopeless one may be, one must learn to be a fighter.

\section{Conclusions: Is multimodality the best way to visualize, negotiate, communicate, and translate hyphenated identities?}

Multimodality looks at the many different modes used by individuals and groups to communicate with each other and to express themselves (Gunther Kress 2010). It includes written, oral, visual, aural, gestural, tactile, spatial and other sign-systems and modalities. Multimodality has become a fully-fledged theoretical framework in the $21^{\text {st }}$ century and has quickly achieved a pivotal role in the study of human communication.

In relation to the issues discussed above, a multimodality approach could prove particularly effective to account for, visualize, negotiate, communicate, and translate 
hyphenated identities where differences, varieties and choices from different cultures are all at play and at once. In terms of Sang's Shaolin Burning, "seeing" this work is more effective than simply reading it in a traditional, one-dimensional format. Besides words, the visual style used to convey the storyline in this Chinese-New Zealand cartoon is particularly successful to appeal to contemporary Chinese women.

First of all, as a point of difference from Chinese Kungfu Comics, the female characters in Shaolin Buring are all painted in a relatively masculine style. It seems that they all have strong muscles and rigid facial lines, details which - I would argue - imply women's power (see Deadly Plum Blossom in the middle in the picture below).

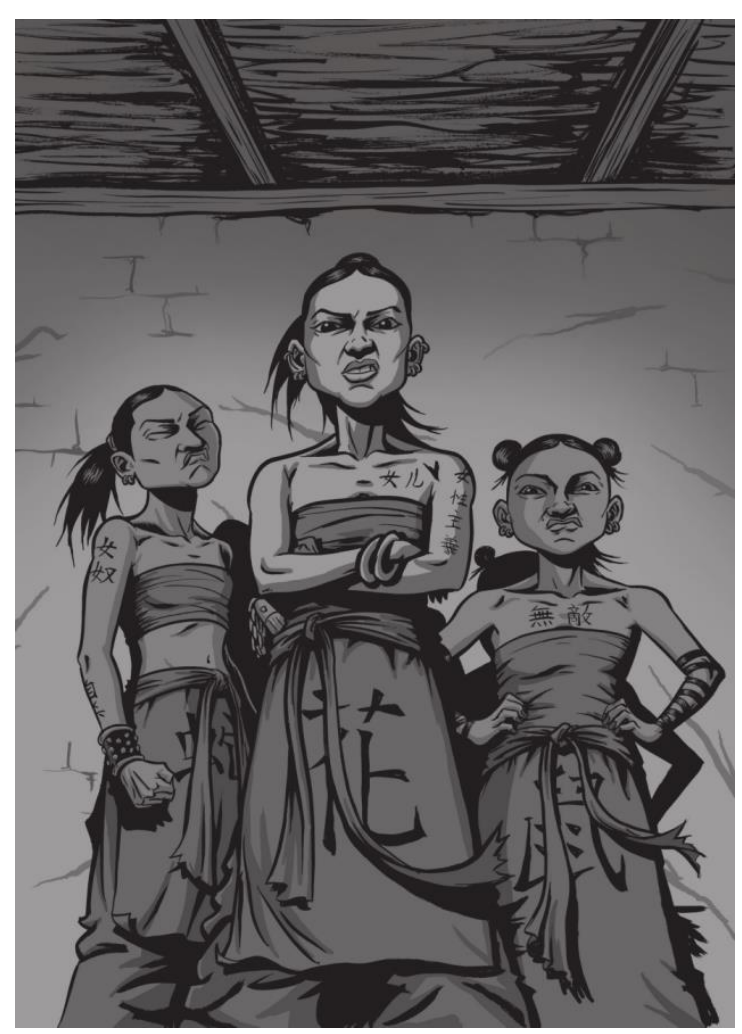

In contrast, Chinese Kungfu cartoonist would depict both female and male characters in a more feminine style - that is, with soft facial lines and slim figures (as in the picture below): 


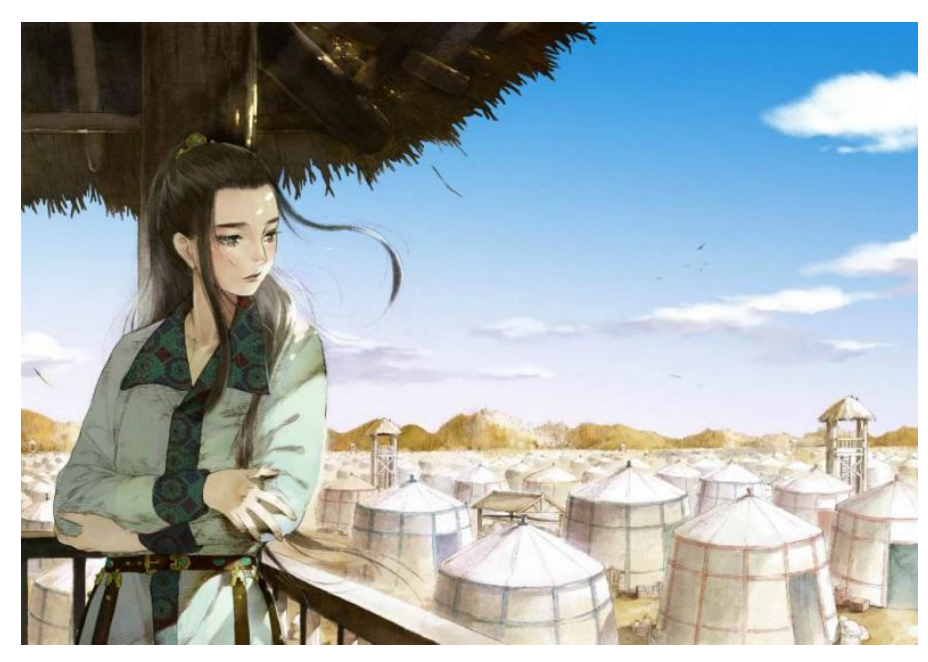

Based on the research I have carried out so far, my interpretation of this difference is that Western Kongfu comics appear to impart on both female and male characters more masculine features whereas Chinese Kungfu comics depict female and male characters with more feminine characteristics. In my opinion, this strong contrast would be appealing to female readers in China, since both male and female characters in Chinese Kungfu comics usually follow an ink-painting, soft-lining and feminine style.

Moreover, in Shaolin Burning Sang has adopted a visual style that integrates Chinese and Western cultures - using the main Western comic style to depict characters while using Chinese elements to design how they wear their clothes and their hair.

The dressing style of the characters in Shaolin Burning is a mixture of Ancient Chinese style and Punk. Their clothes are similar to the Ancient Qing Dynasty costume, but the hairstyle of the male character, earrings, the tattoos and the dark eye circles of some characters are clearly Punk. Think, for example, of Ma Ti Fu Ken, a male Kungfu fighter in the story.

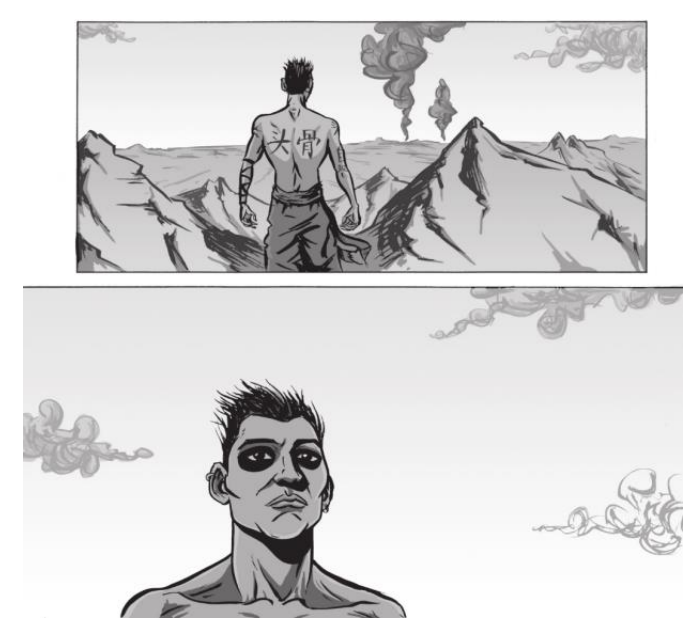

Another interesting point of comparison is that characters from Chinese Kungfu comics wear clothes in a more traditional way. Besides, it not very often that one sees a male character topless in the wild, which is also typical of Punk or Punk-like styles. 


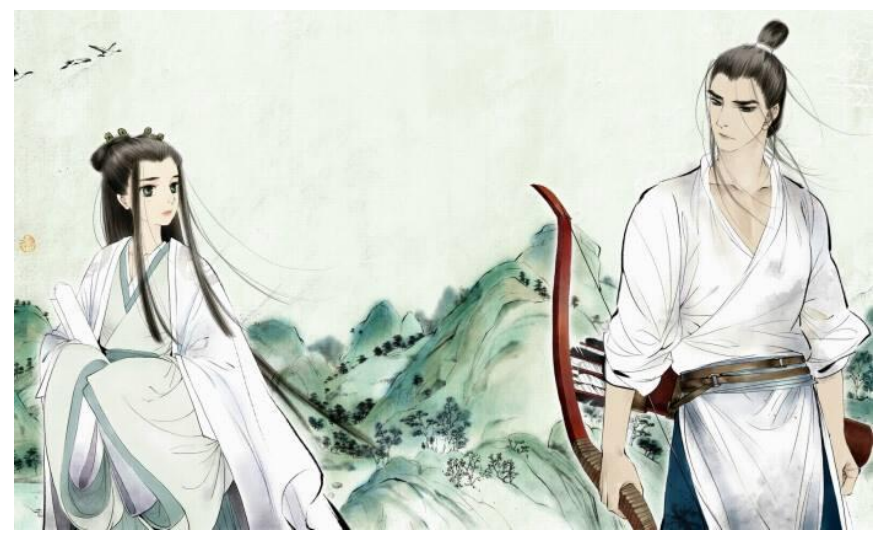

In addition, since the painting style is similar to the main stream of Western comics, such as the Marvel Comics, a younger male readership - I am thinking here of the generations born in the 1990s and 2000s - would also be drawn to Shaoling Burning precisely because it combines their childhood memories as they grow up with reading Marvel Comics and Chinese Kongfu stories!

Overall, "seeing" this work - as I have already mentioned - provides a more effective experience than "reading" it. Ant Sang's visual style, where Chinese and Western cultural footprints are powerfully and purposefully combined to assert female power, is particularly attractive to contemporary Chinese women. Also, as it dialogues with the stories and the styles of Marvel Comics and Kungfu, popular amongst younger Chinese male generations, a male readership in China may also be interested.

In conclusion, it seems clear to me that it is important to study the work of a hyphenatedidentity artist like Ant Sang since his works express and exchange the fingerprints of his cultural heritage. It is also important to draw on multimodality as an ideal theoretical and evaluative framework as it ensures the different cultures are expressed in an inclusive, integrated and informative way. Meanwhile, it is also important to backtranslate the story into the culture where its roots are set - China - not only to showcase women's power but also to better understand the role of two different cultures in one's own identity. Shaolin Burning is like a traditional Kungfu story with revolutionary new ideas transmitted through inter-visual and inter-textual narratives; it combines a lot of Chinese cultural elements, especially Kungfu, with many Western values, beliefs and narratives. I've chosen a more poetic and more 'Kungfu style' to translate excerpts from Ant Sang's Shaolin Burning. For Chinese readers who are fond of Kungfu stories, this approach can impress them especially, since the "Kunfu style" language is a button to trigger their memories and longing for the world of Kungfu.

\section{Selected Bibliography}

\section{Primary Sources}

Shaolin Burning (C) Ant Sang 2004-2016. All Rights Reserved. Developed by Lumière 
Industries.

Secondary Sources

A. Multimodality

1. Norris, Sigrid (ed.). (2012). Multimodality in Practice: Investigating Theory-inpractice-through-methodology. London: Routledge,

2. Monica Boria, Ángeles Carreres, María Noriega-Sánchez, and Marcus Tomalin (eds). (2020). Translation and Multimodality: Beyond Words. London: Routledge.

3. Wildfeuer, Janina (ed.) Building Bridges for Multimodal Research: International Perspectives on Theories and Practices of Multimodal Analysis. Peter Lang.

B. Intersemiotic Translation

1.Kazmierczak, Marta (2017). "From Intersemiotic Translation to Intersemiotic Aspects of Translation". Przekladaniec: A Journal of Literary Translation (1425-6851), 2017(34): 7.

C. Gender Issues

1. Chao, Emily. "Chopsticks Only Work in Pairs": Gender Unity and Gender Equality among the Lahu of Southwest China by Shanshan Du (Columbia University Press, 2002, 237pp), in The China Quarterly, 2004: 823-825.

2. Nakagaki, Yoko. "Fertility, Female Labor Participation and Income in East Asia", International Journal of Development Issues; Bingley, 2018(17): 69-86.

3. Ertan, Senem. "How to Study Gender Equality Policy Cross-Nationally? Aggregate or Disaggregate Gender Equality Policy Indices?”, Social Indicators Research, 2016 (125/1): 47-76.

4. Ministry of Women's Affairs (NZ), Ministry for Women Annual Report 2014/15, https://women.govt.nz/sites/public_files/MFW_2015\%20Annual\%20Report-web.pdf

5. Tania Domett, Gender Equality and the Politics of Work-life Balance in New Zealand, in Kate McMilan, John Leslie \& Elizabeth Mcleay (eds.), Rethinking Woman and Politics: New Zealand and Comparative Perspectives, Victoria University Press, 2009, p. 247.

6. Hongmei Shi, Jie Huang, "New Zealand Feminist Movement: Tracing, Evolution and Thinking", Social Sciences Abroad, 2016(2): 84-92. 


\section{(6) NEKE}

7. Qi Yan York, James Huawen Shen \& Yun Yang, "How 'dama' becomes drama assessing the ideological forces underlying open air group dances by Chinese senior females”, Leisure Studies, 2019, DOI/full/10.1080/02614367.2019.1633681

D. Kungfu

1. Liangjun Yuan, "Jin Yong: A Swordsman Fiction Writer of the 'New Jianxian School", Journal of Chongqing Normal University Edition of Social Sciences, 2003(2): 26-32.

2. Jennifer Yuh \& Alessandro Carloni dir., Kung Fu Panda 3 (2016), China Film Co., Ltd., DreamWorks Animation Film Company, Shanghai Oriental DreamWorks Cultural Communication Co., Ltd. 